Chapter 3

\title{
Chemistry of Natural Antioxidants and Studies Performed with Different Plants Collected in Mexico
}

\author{
Jorge Alberto Mendoza Pérez and \\ Tomás Alejandro Fregoso Aguilar \\ Additional information is available at the end of the chapter \\ http://dx.doi.org/10.5772/52247
}

\section{Introduction}

\subsection{Antioxidants}

Oxidation is the transfer of electrons from one atom to another and represents an essential part of both aerobic life and our metabolism, since oxygen is the ultimate electron acceptor in the electron flow system that produces energy in the form of ATP. However, problems may arise when the electron flow becomes uncoupled (transfer of unpaired single electrons), generating free radicals [1]. Antioxidants are important in living organisms as well as in food because they may delay or stop formation of free radical by giving hydrogen atoms or scavenging them. Oxidative stress is involved in the pathology of cancer, atherosclerosis, malaria and rheumatoid arthritis. An antioxidant can be defined in the broadest sense of the word, as any molecule capable of preventing or delaying oxidation (loss of one or more electrons) from other molecules, usually biological substrates such as lipids, proteins or nucleic acids. The oxidation of such substrates may be initiated by two types of reactive species: free radicals and those species without free radicals are reactive enough to induce the oxidation of substrates such as those mentioned. There are three main types of antioxidants:

1. Primary: Prevent the formation of new free radicals, converting them into less harmful molecules before they can react or preventing the formation of free radicals from other molecules. For example:

- Enzyme superoxide dismutase (SOD) which converts $\mathrm{O}_{2}$ - - to hydrogen peroxide $\left(\mathrm{H}_{2} \mathrm{O}_{2}\right)$ 
- Enzyme glutathione peroxidase (GPx), which converts $\mathrm{H}_{2} \mathrm{O}_{2}$ and lipid peroxides to harmless molecules before they form free radicals.

- Catalases

- Glutathione reductase.

- Glutathione S transferase.

- Proteins that bind to metals (ferritin, transferrin and ceruloplasmin) limit the availability of iron necessary to form the radical $\mathrm{OH}$

2. Secondary: Capture free radicals, preventing the chain reaction (eg vitamin E or alphatocopherol, vitamin $\mathrm{C}$ or ascorbic acid, beta-carotene, uric acid, bilirubin, albumin, ubiquinol-10, methionine)

3. Tertiary: They repair damaged biomolecules by free radicals (eg DNA repair enzymes and methionine sulfoxide reductase) [2].

It also handles the classification based according to where they perform their activities, their background and their biochemical characteristics. So, antioxidants are also classified into two broad groups, depending on whether they are water soluble (hydrophilic) or lipid (hydrophobic). In general, water soluble antioxidants react with oxidants in the cell cytoplasm and blood plasma, whereas the liposoluble antioxidants protecting cell membranes against lipid peroxidation. In the metabolism it is a contradiction that while the vast majority of life requires oxygen for its existence, oxygen is a highly reactive molecule that damages living organisms by producing reactive oxygen species. Therefore, organisms possess a complex network of antioxidant metabolites and enzymes that work together to prevent oxidative damage to cellular components such as DNA, proteins and lipids. Usually antioxidant systems prevent these reactive species are formed or removed before they can damage vital components of the cell. Reactive oxygen species produced in cells include hydrogen peroxide $\left(\mathrm{H}_{2} \mathrm{O}_{2}\right)$, hypochlorous acid $(\mathrm{HClO})$, and free radicals such as hydroxyl radical $(\bullet \mathrm{OH})$ and superoxide radical $\left(\mathrm{O}_{2} \bullet-\right)$. The hydroxyl radical is particularly unstable and reacts rapidly and non-specifically with most biological molecules. This species produces hydrogen peroxide redox reactions catalyzed by metals such as the Fenton reaction. These oxidants can damage cells starting chemical chain reactions such as lipid peroxidation or by oxidizing DNA or DNA damage proteins. These effects can cause mutations and possibly cancer if not reversed by DNA repair mechanisms, while damage proteins will cause enzyme inhibition, denaturation and degradation of proteins. The use of oxygen as part of the process for generating metabolic energy produces reactive oxygen species. In this process, the superoxide anion is produced as a byproduct of several steps in the electron transport chain. Particularly important is the reduction of coenzyme $Q$ in the compound III as a highly reactive free radical is formed as intermediate $(\mathrm{Q} \bullet-)$. This unstable intermediate can lead to loss of electrons when these jump directly to molecular oxygen to form superoxide anion instead of moving with well controlled series of reactions of electron transport chain. In a similar set of reactions in plants reactive oxygen species are also produced during photosynthesis under high light intensity. This effect is partly offset by the involvement of carotenoids in photoin- 
hibition, which involves these antioxidants reacting with over-reduced forms of the photosynthetic reaction centers and thereby prevent the production of superoxide. Another process which produces reactive oxygen species is lipid oxidation that takes place following the production of eicosanoids. However, the cells are provided with mechanisms that prevent unnecessary oxidation. Oxidative enzymes of these biosynthetic pathways are coordinated and highly regulated [3].

\subsection{Free radicals}

A free radical from the chemical viewpoint, is any species (atom, molecule or ion) containing at least one unpaired electron and its outermost orbital, and which is in turn able to exist independently (Figure 1).

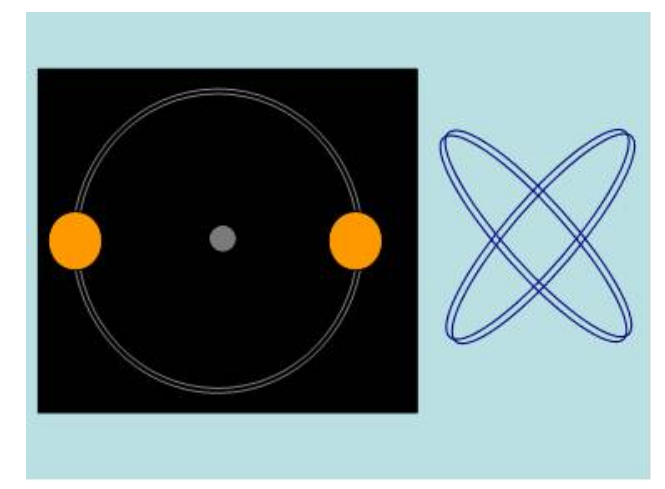

Figure 1. Atomic orbitals

The atoms arrange their electrons in regions called "atomic orbitals" in the form of pairs of electrons. The latter confers stability atom, or low chemical reactivity towards its environment. However, under certain circumstances, it may lose its parity orbital, either giving or capturing an electron. When this occurs, the resulting orbit exhibits an unpaired electron, making the atom in a free radical. The presence of an unpaired electron in an orbital outermost atom latter confers an increased ability to react with other atoms and / or molecules present in the environment, usually, lipids, proteins and nucleic acids (Figure 2). The interaction between free radicals and such substrates results in eventually structural and functional alterations [4].

Free radicals cause damage to different levels in the cell: Attack lipids and proteins in the cell membrane so the cell cannot perform its vital functions (transport of nutrients, waste disposal, cell division, etc.).

The superoxide radical, $\mathrm{O}_{2}$, which is normally in the metabolism cause a chain reaction of lipid peroxidation of the fatty acids of phospholipids of the cell membrane. Free radicals attack DNA avoiding cell replication and contributing to cellular aging. 


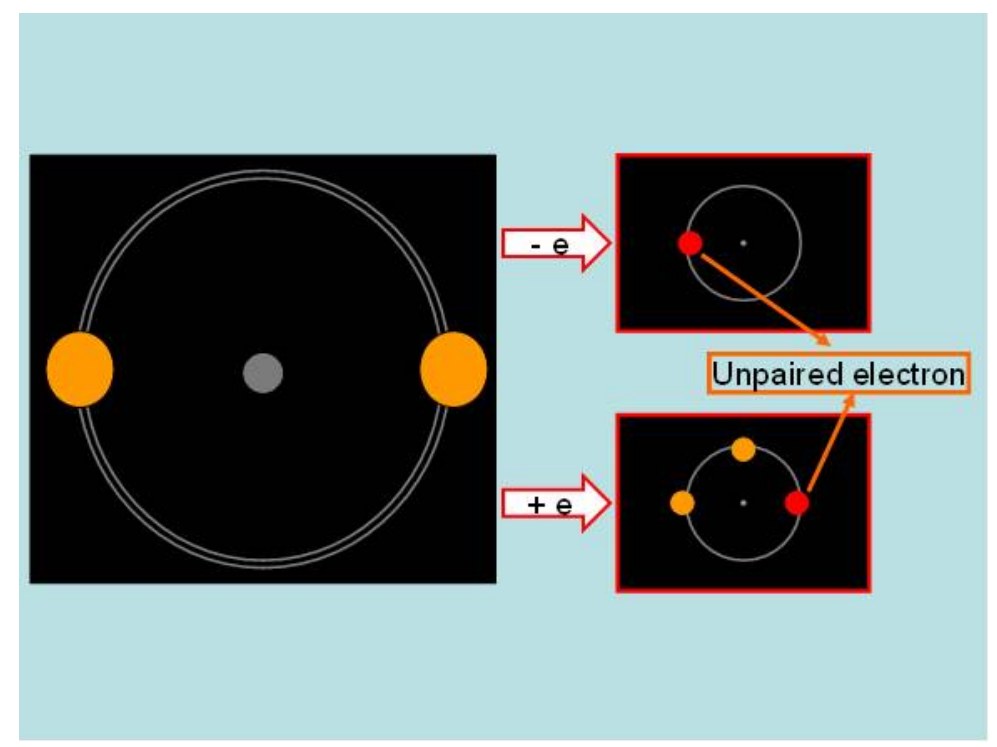

Figure 2. Unpaired electron in a free radical

The normal body processes produce free radicals that involve food metabolism, breathing and exercise. We are also exposed to environmental elements that create free radicals such as industrial pollution, snuff, radiation, drugs, chemical additives in processed foods and pesticides. Not all free radicals are dangerous because, for example, immune cells create free radicals to kill bacteria and viruses, but if there is sufficient control by antioxidants, healthy cell can be damaged.

The reactive oxygen species (ROS) is a collective term, widely used, comprising all the reactive species, whether or not free radicals, focus their reactivity in an oxygen atom. However, often under the designation ROS include other chemical species whose reactivity is focused on other than oxygen atoms [5].

\subsection{Metabolites}

In general, water soluble antioxidants react with oxidants in the cell cytoplasm and blood plasma, whereas the liposoluble antioxidants protecting cell membranes against lipid peroxidation. These compounds can be synthesized in the body or obtained from the diet (Table 1) [6].

\subsection{Antioxidant metabolites in plants}

Plants produce many different secondary metabolites some of them are potent antioxidants, some examples of these compounds is shown in Figure $3[5,7]$. 


\begin{tabular}{|c|c|c|c|}
\hline Antioxidant metabolite & Solubility & $\begin{array}{l}\text { Concentration in human } \\
\text { serum (M) }\end{array}$ & $\begin{array}{l}\text { Liver tissue concentration } \\
\qquad(\mathrm{mol} / \mathrm{kg})\end{array}$ \\
\hline Ascorbic acid (vitamin C) & Water & 50 to 60 & 260 (male) \\
\hline Glutathione & Water & from 325 to 650 & 6,400 (male) \\
\hline Lipoic acid & Water & from 0.1 to 0.7 & 4- 5 (rat) \\
\hline Uric acid & Water & from 200 to 400 & 1,600 (male) \\
\hline Carotene & Lipid & $\beta$-carotene: 0.5 to 1 & $\begin{array}{l}\text { retinol (vitamin A): } 1 \text { - } 35 \\
\text { (male, total carotenoids) }\end{array}$ \\
\hline $\begin{array}{l}\text { a-tocopherol } \\
\text { (vitamin E) }\end{array}$ & Lipid & 10 to 40 & 50 (male) \\
\hline Ubiquinol (coenzyme Q) & Lipid & 5 & 200 (male) \\
\hline
\end{tabular}

Table 1. Biochemical properties of antioxidant metabolites
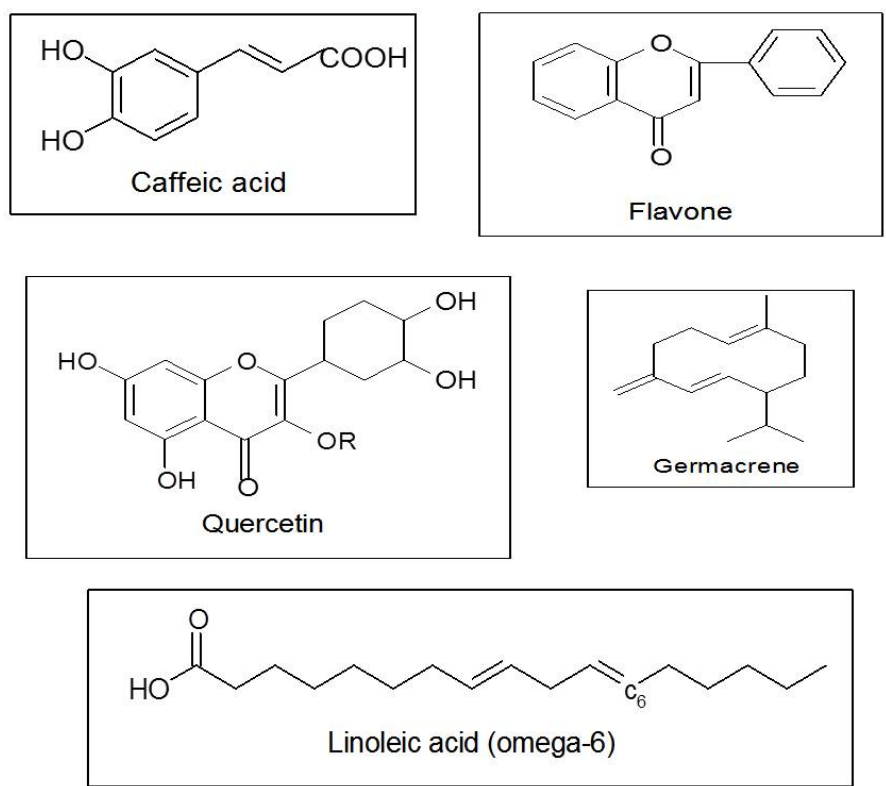

Figure 3. Different kinds of antioxidant metaboilites produced by plants

\section{Enzyme systems}

As with chemical antioxidants, cells are protected against oxidative stress by a network of antioxidant enzymes. Superoxide released by processes such as oxidative phosphorylation, 
is first converted into hydrogen peroxide and immediately reduced to give water. This route of detoxification is the result of multiple enzymes with superoxide dismutase catalyzing the first step and then catalases and peroxidases that eliminate several hydrogen peroxide [8].

\subsection{Oxidative stress}

Free radicals oxidize many biological structures, damaging them. This is known as oxidative damage, a major cause of aging, cancer, atherosclerosis, chronic inflammatory processes and cataracts, which are the most characteristic.

In certain circumstances, production of free radicals can increase uncontrollably, a situation known as oxidative stress. This means an imbalance between the speeds of production and destruction of toxic molecules, leading to an increase in cellular concentration of free radicals. Cells have mechanisms to protect against the harmful effects of free radicals based on a complex defense mechanism consisting of the antioxidants. Oxidative stress has been implicated in over one hundred human disease conditions, such as cancer, cardiovascular disease, aging and neurodegenerative diseases [9]. However, the innate defense in the human body may not be enough for severe oxidative stress. Hence, certain amounts of exogenous antioxidants are constantly required to maintain an adequate level of antioxidants in order to balance the ROS. As an example, epidemiological evidence indicates that the consumption of grapes reduces the incidence of coronary heart disease (CHD), atherosclerosis and platelet aggregation [10]. This greater protection may be due to the phenolic components of grapes, which are particularly abundant since they behave as reactive oxygen species-scavengers and metal-chelators. Polyphenolic substances in grapes and other red fruits are usually subdivided into two groups: flavonoids and nonflavonoids. The most common flavonoids are flavonols (quercetin, kaempferol, and myricetin), flavan-3-ols (catechin, epicatechin, and tannins), and anthocyanins (cyanin). Nonflavonoids comprise stilbenes, hydroxycinnamic acids and benzoic acids. Numerous papers have been published red fruits and their antioxidant properties have been correlated with their polyphenol contents $[11,12,13,14,15]$.

\subsection{Oxidative stress and disease}

It is thought that oxidative stress contributes to the development of a wide range of diseases including Alzheimer's disease, Parkinson's disease, the pathologies caused by diabetes, rheumatoid arthritis, and neurodegeneration in motor neuron diseases. In many cases, it is unclear if oxidants trigger the disease, or occur as a result of this and cause the symptoms of the disease as a plausible alternative, a neurodegenerative disease may result from defective axonal transport of mitochondria that perform oxidation reactions. A case in which it fits is particularly well understood in the role of oxidative stress in cardiovascular disease. Here, the oxidation of low density lipoprotein (LDL) seems to trigger the process of atherogenesis, which leads to atherosclerosis, and ultimately to cardiovascular disease.

In diseases that have a high impact on the health sector Diabetes Mellitus is one of the most known. The World Health Organization (WHO) estimates that there are just over 180 mil- 
lion diabetics worldwide and likely to double this number for 2030 is quite high. Countries like China, India, United States of America and Mexico are at the top of this pathology [16]. In Mexico, this condition is a major cause of mortality and morbidity are estimated to be approximately 10 million individuals with diabetes, of whom $22.7 \%$ did not know they are sick, while $55 \%$ do not have good control netheir condition. This pathology is multifactorial, presenting various metabolic problems (polyuria, polyphagia, polydipsia, weight changes). The disorder is characterized by the inadequate use of glucose, due to insufficient production, insulin resistance and some without production of the hormone, resulting in unfavorable a high index of this monosaccharide in the blood. This causes abnormal function of some organs, tissues and systems that can cause kidney failure, vision loss, and amputation of a limb, diabetic coma and even death.

Different factors increase the likelihood of the individual to develop diabetes as are smoking, sedentary lifestyle, lack of exercise coupled with unbalanced diet causes both overweight and obesity. Naturally the body causes the formation of free radicals (highly unstable molecules), these chemical species are responsible for cellular aging, but when there is a greater concentration of these molecules may contribute to the development of various diseases and chronic degenerative neuro Parkinson's, Alzheimer's and diabetes. Obesity increases oxygen consumption and thus the production of free radicals, thus creating the phenomenon known as oxidative stress. Excess fat naturally stored in fat cells, causes the more than normal synthesis of substances called adiposines IL6 or leptines. These substances in higher concentrations also cause insulin resistance [17].

\section{Alternative medicine}

Due to the current problem in the health issue we propose the use of herbs as an option to improve the style of living of the people, not only for the adjuvant treatment, but because the use of plants offers great nutritional benefits somehow reducing the incidence of such chronic degenerative diseases. This is not intended to impair the option of preventive diagnosis by the health sector does not provide such benefits, but rather the use of plants known to have medicinal activity coupled with the clinical - pharmacology, could present better results, for the treatment of the various degenerative chronic diseases. Given the increasing scientific evidence that the etiology of several chronic degenerative diseases such as diabetes is influenced by factors such as metabolic redox imbalance. Is currently booming studying the formation of metabolites against free radicals that diverse plant species presents. An example of this has been widely documented, is the cranberry, a plant used for treating various diseases and, as has been discovered, is due to its potential antioxidant that has these properties beneficial to health [18, 19].

Similarly, Mexico has focused attention on other plants with potential antioxidant properties and for some years and was used in the treatment of diabetes. In this regard, since 2006, our research work focused on the task of describing the effects of plants such as Noni (Morinda citrifolia), Moringa (Moringa oleifera), the Guarumbo (Cecropia obtusifolia Bertolt), the Musaro 
(Lophocereus sp.) and Neem (Azadirachta indica) in murine models of chemically induced diabetes with streptozotocine. More recently, we began to evaluate the antioxidant properties of some of these plants through in vitro techniques [20].

\subsection{Antioxidant effects in Mexican plants}

The use of traditional medicine is widespread in Mexico and plants are indeed the first source for preparing remedies in this form of alternative medicine. Among the various compounds found in plants, antioxidants are of particular importance because they might serve as leads for the development of novel drugs. Several plants used as anti-inflammatory, digestive, antinecrotic, neuroprotective, and hepatoprotective properties have recently been shown to have and antioxidant and/or antiradical scavenging mechanism as part of their activity [21,22]. The search for natural sources of medicinal products that also have antioxidant and radical scavenging activity is on the rise [23,24]. Among the medicinal properties associated with them are the following: the fruitand bark of Licania arborea is used as a soap for hair infections, the latex from Ficus obtusifolia is employed as an anti parasitic and also for reducing fever, Bunchosia cannesens is prescribed as an antidiarrhoeic, Sideroxylon capiri is used for hiccups, as an antiseptic for cleaning wounds, and women use its leaves in a water bath after giving birth. The latex of Sapium macrocarpum is used against scorpion stings, fever and some skin problems such as warts; its use as an anti-coagulant is also widespread. The latex of Ficus cotinifolia is used in the treatments of urinary infections, vomiting, malaria and against inflammatory pathologies of the spleen. The leaves of Annona squamosa are used in cicatrisation of wounds, diarrhoea, ulcers, menstrual disorders, and also to help weight loss. The seeds of this plant are also employed as an insecticide. The leaves of Vitex molli are used to treat stomach ache, digestion disorders, nervous alterations, and also scorpion stings. Piper leucophyllum is employed for reducing fever and its dried leaves are used for cleaning eyes and as spice in cooking. The leaves and bark of Gliricidia sepium are used against high fever, skin infections, urine disorders, malaria, and headache. However, its seeds are reported to be toxic. Hamelia paten is used to accelerate wound cicatrisation. The Mexican and Central America native species of Astianthus viminalis is used for the curing of diabetes and malaria and to reduce hair loss. Swietenia humilis is used as anti parasitic, and it is also utilized for hair care as a shampoo. It is also used with other plants in mixed herbal teas, and used as home remedies. Stemmandenia bella is employed for curing wounds; Rupechtia fusca is used in some stomach disorders; Bursera grandifolia is used as a tooth paste and against digestive disorders; Ziziphus amole is prepared as infusion and it is applied for washing wounds and to treat gastric ulcers. The fruit and the latex of Jacaratia mexicana are used against ulcers in the mouth and digestive disorders. Gyrocarpus jathrophifolius leaves and bark are used as an analgesic. Pseudobombax ellipticum is used in respiratory disorders such as cough, and also against fever and as an anti microbial. The stems and flowers of Comocladia engleriana are toxic because they produce dermatitis. The flowers and the latex of Plumeria rubra can be used for stopping vaginal blood shed, and toothache, and the latex of the plant is used against earache. Infusions are used as an Eye-cleaning liquid [23, $24,25 \& 26]$. 
Polyphenolic compounds are commonly found in both edible and inedible plants, and they have been reported to have multiple biological effects, including antioxidant activity [25]. Herbs are used in many domains, including medicine, nutrition, flavouring, beverages, dyeing, repellents, fragrances, cosmetics [26]. Many species have been recognized to have medicinal properties and beneficial impact on health, e.g. antioxidant activity, digestive stimulation action, antiinflammatory, antimicrobial, hypolipidemic, antimutagenic effects and anticarcinogenic potential $[27,28]$. Crude extracts of herbs and spices, and other plant materials rich in phenolics are of increasing interest in the food industry because they retard oxidative degradation of lipids and thereby improve the quality and nutritional value of food. The basic flavonoids structure is the flavan nucleus, which consists of 15 carbon atoms arranged in three rings (C6-C3-C6), labelled A, B, and C (Figure 3). Various clases of flavonoid differ in the level of oxidation and saturation of ring $C$, while individual compounds within a class differ in the substitution pattern of rings $\mathrm{A}$ and $\mathrm{B}$. The differences in the structure and substitution will influence the phenoxyl radical stability and thereby the antioxidant properties of the flavonoids. Plant species belong to several botanical families, such as Labiatae, Compositae, Umbelliferae, Asteracae, Polygonacae and Myrtacae. Many spices have been investigated for their antioxidant properties for at least 50 years $[29,30]$.

\section{DPPH experiments with different plants collected in México}

Herein it is presented a brief description of two experiments to evaluate the antioxidant properties of some plants collected in México, one conducted in the Moringa tree (Moringa oleifera) and the other in the Neem tree (Azadirachta indica).

1. Antioxidant properties of Moringa oleifera: In this experiment were collected fresh leaves of M. oleifera in the Municipality of Apatzingan in the state of Michoacan, Mexico, the leaves are brought to the facilities of the National School of Biological Sciences, IPN where allowed to air dry and then were macerated and placed in containers containing methanol. After one week the solvent was decanted and concentrated under reduced pressure using a rotary evaporator. The crude methanol extract was stable in distilled water obtained the following experimental concentrations: 50, 25, 12.5 and $6.25 \mathrm{mg} / \mathrm{mL}$ to which they evaluated the antioxidant capacity.

It was used as standard test the unstable radical 2,2-diphenyl-picrylhydrazyl (DPPH), which originally has a purple and when it is placed against a substance having antioxidant properties in a UV spectrophotometer at $517 \mathrm{~nm}$, changes to yellow colour yellow (Figure 4). It was prepared a calibration curve of DPPH type in methanol at concentrations of 40,120, 160 and $200 \mathrm{ug}$. Subsequently, aliquots of the above concentrations of methanol extract of $M$. oleifera and combined with DPPH in methanol for measuring its absorbance in the UV spectrophotometer at 0, 10, 30, $6045 \mathrm{~min}$., and then self-assess their antioxidant capacity [31]. 


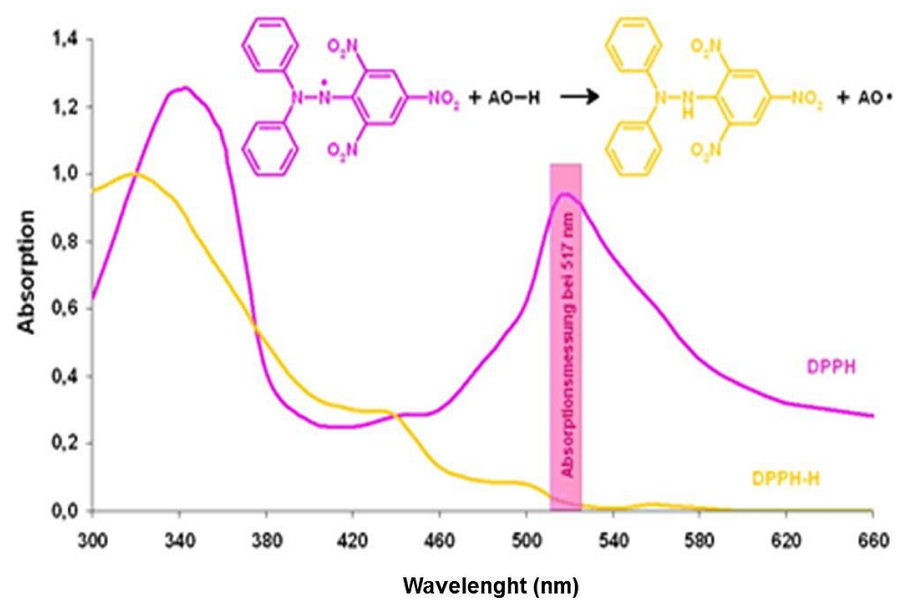

Figure 4. Graph showing the colour change of DPPH from purple to yellow when it is exposed to an antioxidant substance

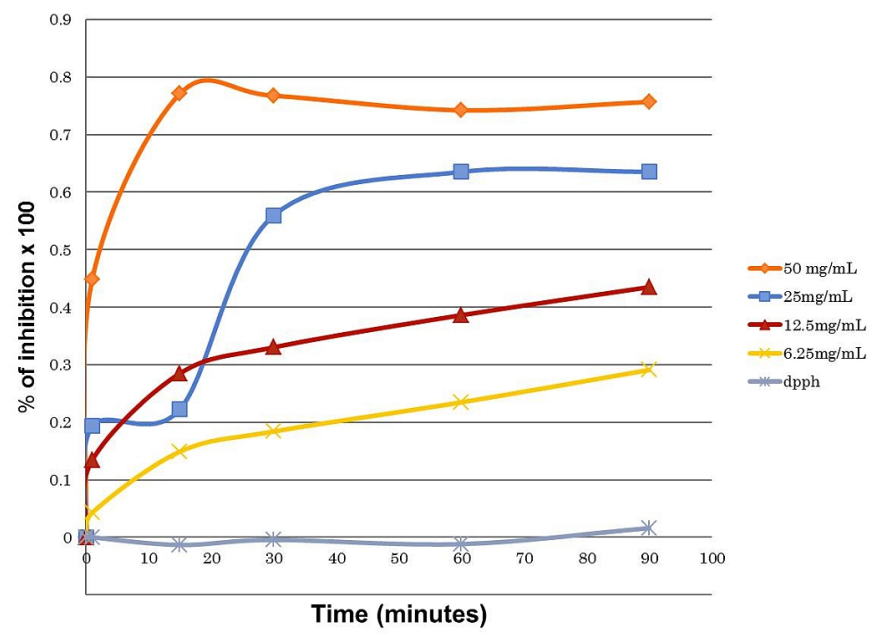

Figure 5. Antioxidant activity of different concentrations of methanol extract of M. oleifera

It was found that higher concentrations of M. oleifera antioxidant activity showed a concentration dependance, ie the higher the concentration of the extract metabolic higher antioxidant capacity (Figure 5). It was noted that the highest concentrations (50 mg / $\mathrm{mL}$ and 25 $\mathrm{mg} / \mathrm{mL}$ ) reached $50 \%$ of its antioxidant activity (assessed by the percentage of inhibition of purple fading to yellow against DPPH respective concentration of the methanol extract of M. oleifera) within $10 \mathrm{~min}$. the reaction is initiated, which is indicative of the high antioxidant 
capacity of this plant and that could explain its therapeutic efficacy in the treatment of diabetes in mouse models that are currently underway [32].

2. Comparison of the antioxidant properties of Azadirachta indica with other species and a commercial product. This experiment followed a similar protocol to that described for M. oleifera, with the exception that the samples were evaluated for their antioxidant capacity at times 1, 15, 30, 60 and 90 minutes. The protocol is divided into two parts, one of which was evaluated for antioxidant activity from four different extracts from leaves of Azadirachta indica: a) methanol, b) infusion, c) ethyl acetate and d) ethanol. This was done by measuring the percent inhibition of loss of the color purple to yellow the respective front DPPH extract (Figure 6). It was found that infusion of Neem showed the highest antioxidant activity ( $80 \%$ inhibition) than the other extracts even from the first minute after initiating the reaction. This would correspond to the ethnomedical use that people from rural zones done with this tree, and then take it as a tea before the first food of the day. The methanol extract of Neem leaves also exhibited a high antioxidant capacity, as a percentage inhibition of the radical DPPH greater than $50 \%$ during the entire reaction time [33].

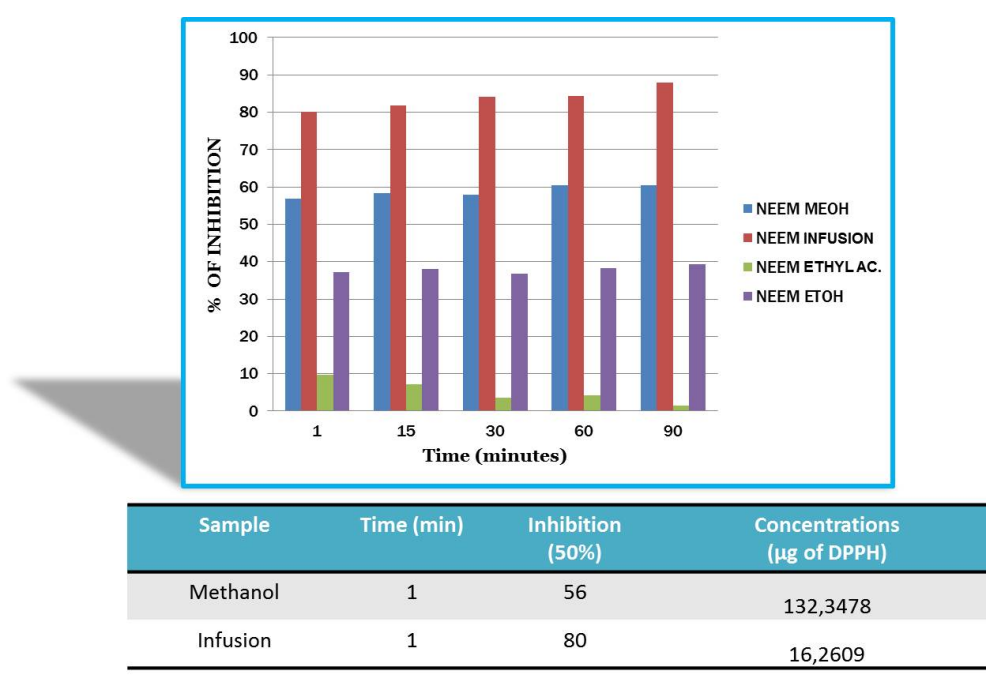

Figure 6. Assessment of\% inhibition of DPPH radical from 4 extracts of Neem (Azadirachta indica).

In the second part of this protocol, we chose a fraction of the methanol extract of Neem leaves and their antioxidant activity was compared against a commercial preparation, a kind of juice containing: Pomegranate (Punica granatum) green tea (Camel sinensis), cranberry (Vaccinum mytillus), red grape (Vitis vinifera) and methanol extract of leaves, seed and fruit peel of passion fruit (Passiflora edulis). It was found that the commercial preparation showed the highest antioxidant activity throughout the reaction time (Figure 7), presented as a\% inhibition greater than $50 \%$ from the first minute $(68 \%$ inhibition), reaching end of the reaction with values high- 
er than $85 \%$ inhibition of the presence of radical DPPH. Compared to the various organs of Passiflora edulis, the Neem leaf extract showed higher antioxidant capacity from the reaction started, it displayed a\% inhibition of DPPH radical by $66 \%$ to reach 15 minutes of reaction, and reaching values greater than $85 \%$ inhibition at 60 minutes, falling a little activivty $(63 \%$ approximately) at $90 \mathrm{~min}$. the reaction is initiated. This would confirm previous data of different authors and from our laboratory (unpublished data), in the sense of the effectiveness of Neem tree leaves for the treatment of chronic degenerative diseases such as diabetes, it has proven effective in significantly reducing blood glucose levels in streptozotocin-treated mice, an effect that may be due to the presence of secondary metabolites of the steroid type saponins, flavonoids and phenols among others that seem to owe much its hypoglycemic action, thanks to its antioxidant properties. In this regard, our laboratory is conducting a more rigorous characterization of secondary metabolites found in these plants by using spectroscopic techniques (e.g, Infrared Spectroscopy with Fourier Transform, Proton Nuclear Magnetic Resonance, etc.) trying to isolate, purify these metabolites and test its therapeutic efficacy in animal models of diabetes. However, we should mention that, although the future is promising with regard to therapy options offered by these plants in Mexico (and other developing countries), yet to be made deeper studies and comparative scale phytochemical, toxicological and drug to confirm everything mentioned in this chapter [34].

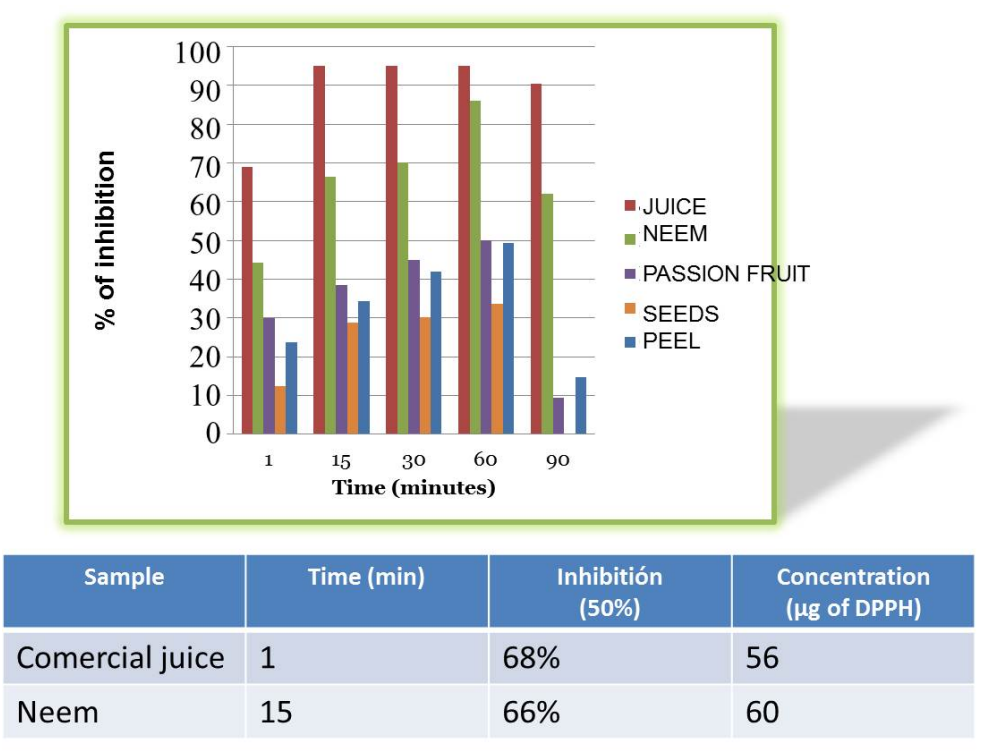

Figure 7. Assessment of\% inhibition of DPPH radical of Neem (Azadirachta indica) with respect to a commercial preparation and different organs of Passion fruit (Passiflora edulis).

Another experiment with Noni (Morinda citrifolia) showed that the leaves of this plant also have a high antioxidant effect at low concentrations reaching a maximum effect at a dose of $5 \mathrm{mg} / \mathrm{mL}$ (Figure 8 ). These results disagreed with the effect observed with the Noni fruit, 
where it was reported that the antioxidant effect of protection tends to increase with respect to higher concentrations in tests performed with lyophilized juice extracts [35].

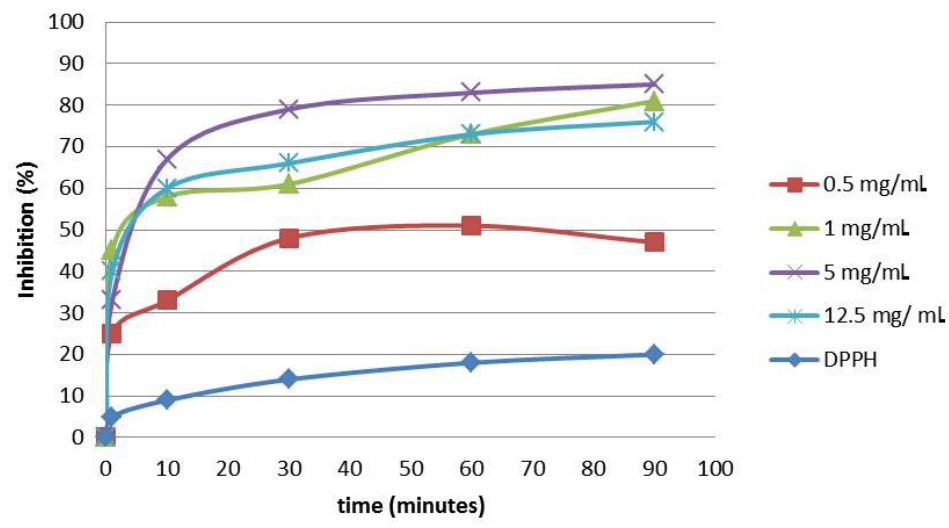

Figure 8. Results from DPPH method for testing the free-radical inhibition effect of different concentrations of methanolic extracts of Noni leaves.

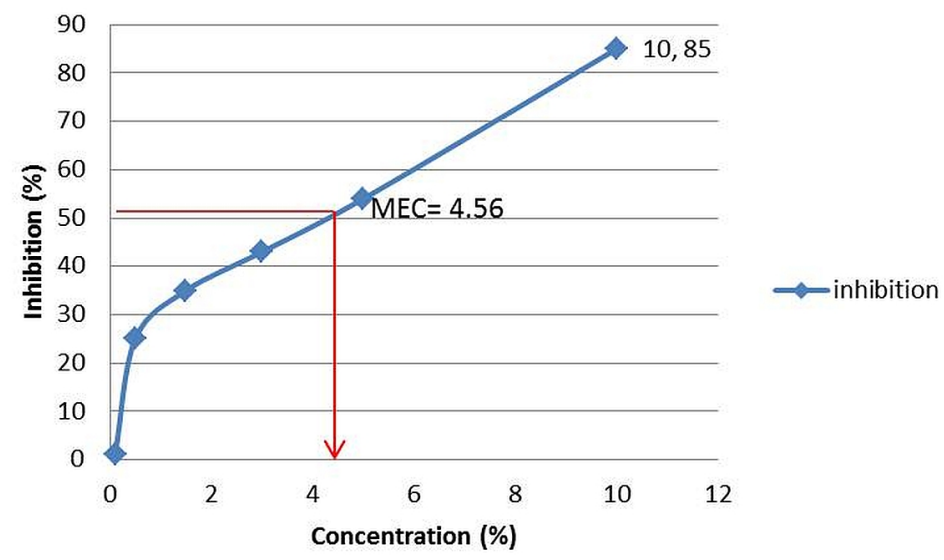

Figure 9. Shows the curve concentration vs. inhibition (\%) of the radical 1,1-diphenyl-2-picrylhydrazyl (DPPH $\bullet$ ), in which it is observed that the mean effective concentration (MEC) of noni leaf extract was 4,56\%, at this concentration is carried out the $50 \%$ inhibition of the unpaired radical.

Furthermore a methanolic solution was prepared with a concentration of $860 \mathrm{mmol} / \mathrm{mL}$ of DPPH. From this concentration the experiment was performed with a duplicated calibration curve at different concentrations, which was read at $517 \mathrm{~nm}$. An average concentration of 
those used for standard curve analysis was chosen for the initial concentration of the methanol extract from leaves of Morinda citrifolia. From this methanol extract different percentage dilutions were prepared. After obtaining the extract dilutions $1000 \mu \mathrm{L}$ of each one was mixed with $860 \mu \mathrm{L}$ methanol and $140 \mu \mathrm{L}$ of DDPH and after that it were allowed to stand for $10 \mathrm{mi}-$ nutes at $30^{\circ} \mathrm{C}$ and then absorbance was read (517nm) at time intervals of 10, 30, 45 and 60 minutes in a UV-Vis spectrophotometer HACH DR 5000. Through a mathematical analysis of linear regression curve was obtained concentration vs. inhibition (\%), and finally determined the mean effective antioxidant concentration (Figure 9) [36].

\section{Phytochemical results}

\subsection{Moringa oleifera}

Extraction by maceration from $M$. Oleifera leaves was carried out in methyl alcohol for the phytochemical sieve, the results are shown in the following table (Table 2), and qualitative tests that were performed for each secondary metabolite are named in the same table.

\begin{tabular}{|c|c|c|}
\hline \multirow{6}{*}{ Alkaloids } & Reagent & Test \\
\hline & Dragendorf & ++ \\
\hline & Mayer & + \\
\hline & Wagner & + \\
\hline & Sonneshain & + \\
\hline & Silicotungstine & + \\
\hline Tanines & ferric chloride & - \\
\hline phenols & Potassium ferricianide & + \\
\hline \multirow{2}{*}{ reducing sugars } & Fehling & - \\
\hline & Benedic & - \\
\hline \multirow{2}{*}{ Coumarins } & ammonium hydroxide & - \\
\hline & Erlich & + \\
\hline Flavonoids & Sodium Hydroxide & + \\
\hline Sesquiterpenlactones & hidroxylamine chlorehydrate & - \\
\hline Saponines & Libermann Bouchard & + \\
\hline cardiotonic Glycosides & Kedde, Baljet, legal & - \\
\hline cyanogenic Glycosides & Guignar & - \\
\hline
\end{tabular}

Table 2. Phytochemical sieve of methanolic extract from $M$. olerifera leaves. 


\begin{tabular}{|c|c|c|c|c|c|}
\hline \multirow[b]{2}{*}{ Metabolites } & \multirow[b]{2}{*}{ Reagent } & \multicolumn{4}{|c|}{ Test } \\
\hline & & $\begin{array}{l}\text { Azadirachta } \\
\text { indica }\end{array}$ & $\begin{array}{c}\text { Cecropia obtusifolia } \\
\text { Bertolt }\end{array}$ & Lophocereus sp & $\begin{array}{l}\text { Morinda } \\
\text { citrifolia }\end{array}$ \\
\hline \multirow{5}{*}{ Alkaloids } & Dragendorf & ++ & - & ++ & - \\
\hline & Mayer & + & + & + & + \\
\hline & Wagner & + & - & + & + \\
\hline & Sonneshain & + & - & - & - \\
\hline & Silicotungstine & + & - & - & - \\
\hline Tanines & ferric chloride & - & + & - & - \\
\hline phenols & $\begin{array}{l}\text { Potassium } \\
\text { ferricianide }\end{array}$ & + & + & + & + \\
\hline \multirow{2}{*}{ reducing sugars } & Fehling & - & - & + & + \\
\hline & Benedic & - & - & + & + \\
\hline \multirow[t]{2}{*}{ Coumarins } & $\begin{array}{l}\text { ammonium } \\
\text { hydroxide }\end{array}$ & - & - & + & + \\
\hline & Erlich & + & + & + & + \\
\hline Flavonoids & $\begin{array}{l}\text { Sodium } \\
\text { Hydroxide }\end{array}$ & + & + & - & + \\
\hline Sesquiterpenlactones & $\begin{array}{l}\text { hidroxylamine } \\
\text { chlorehydrate }\end{array}$ & - & + & - & - \\
\hline Saponines & $\begin{array}{l}\text { Libermann } \\
\text { Bouchard }\end{array}$ & + & + & + & + \\
\hline $\begin{array}{l}\text { cardiotonic } \\
\text { Glycosides }\end{array}$ & $\begin{array}{l}\text { Kedde, Baljet, } \\
\text { legal }\end{array}$ & - & + & - & + \\
\hline $\begin{array}{l}\text { cyanogenic } \\
\text { Glycosides }\end{array}$ & Guignar & - & + & + & - \\
\hline
\end{tabular}

Table 3. Phytochemical sieve of different plants collected in Mexico. All the tests were performed with methanolic extracts of the leaves.

The results of this phytochemical analysis presented in Table 2, shows qualitatively the secondary metabolites found in the methanol extract of leaves of M. oleifera. The more abundant compounds in the leaves of this tree and also the must reported in several articles are:
i. Alkaloids
ii. Coumarins
iii. Phenolics
iv. Flavonoids 
v. Saponins

In the case of metabolites such as tannins, cardiac glycosides, cyanogenic glycosides, the tests results were negative for the methanol extract of leaves of M. oleifera $[37,38]$.

Phytochemical results for the extracts obtained from leaves of Guarumbo (Cecropia obtusifolia Bertolt), Musaro (Lophocereus sp.), Neem (Azadirachta indica) and Noni (Morinda citrifolia) are showed in Table 3. Several of those metabolites are highly active antioxidants.

\section{Description of those plants collected in México and presenting high content of antioxidant compounds}

\subsection{Azadirachta indica}

Active compounds of Neem have been identified while others have not, and analyzed the most common are: nimbin; nimbidin; ninbidol; gedunin; sodium nimbinate; queceretin; salannin and azadirachtin.

Parts used and their uses:

Neem bark is bitter, astringent, is used to treat diseases of the mouth, teeth, loss of appetite, fever, cough and intestinal parasites (Figure 10)

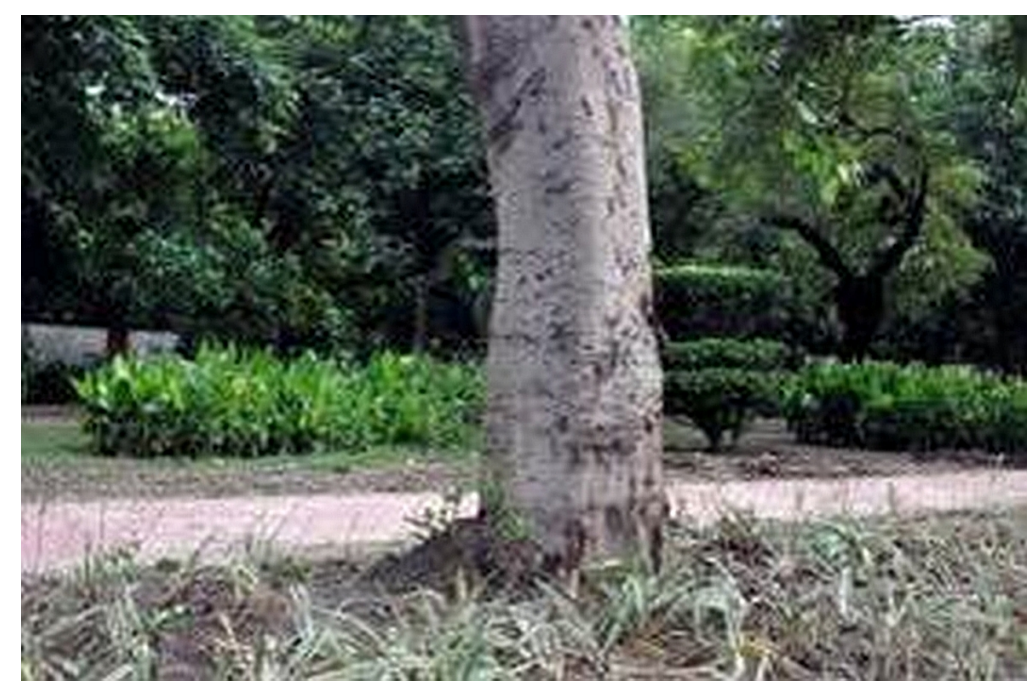

Figure 10. Stem of the Neem tree.

The leaves help to neuromuscular problems, eliminate toxins, purify the blood, are also used to treat snake bites and insect (Figure 11) 


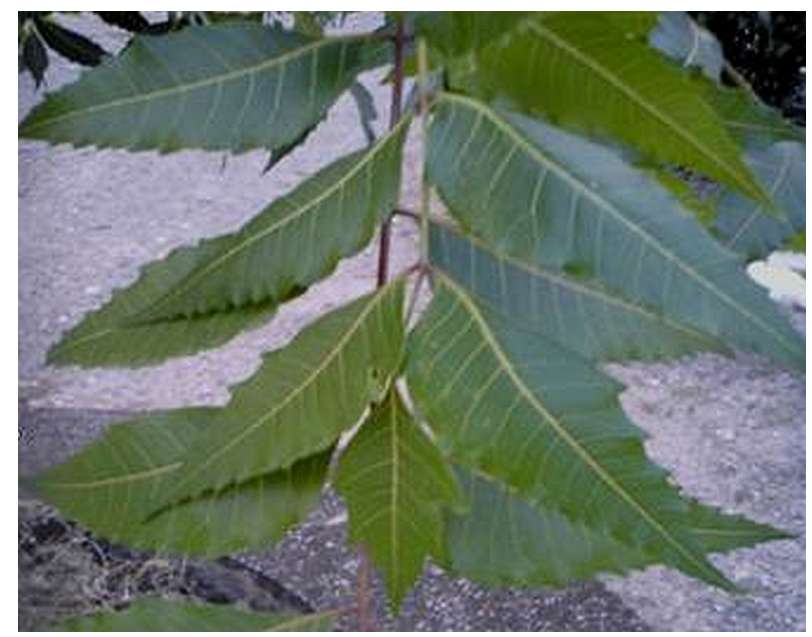

Figure 11. Branch and leaves of Neem or Azadirachta indica.

The Neem fruit is bitter, and it is used as a purgative and for hemorrhoids (Figure 12)

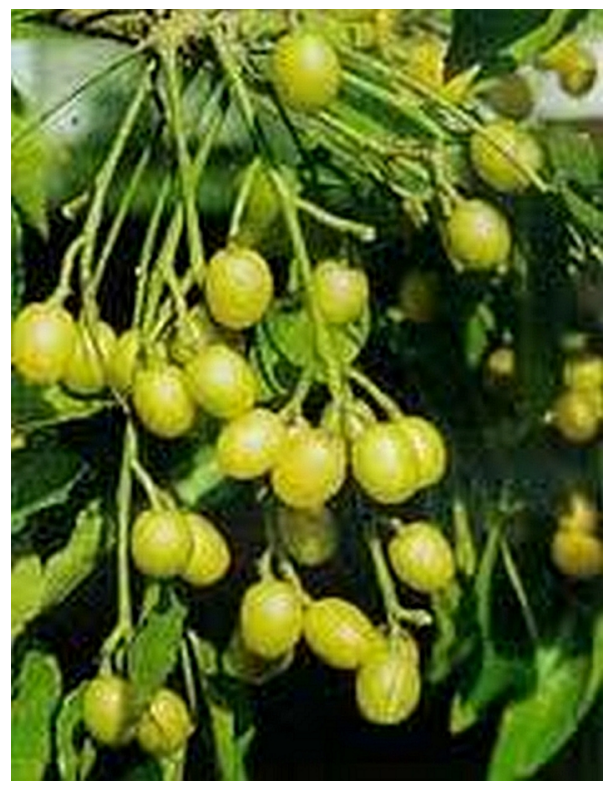

Figure 12. Fruits from Neem Tree

The flowers are astringent and expectorant and also Seed oil is extracted. (Figure 13). 


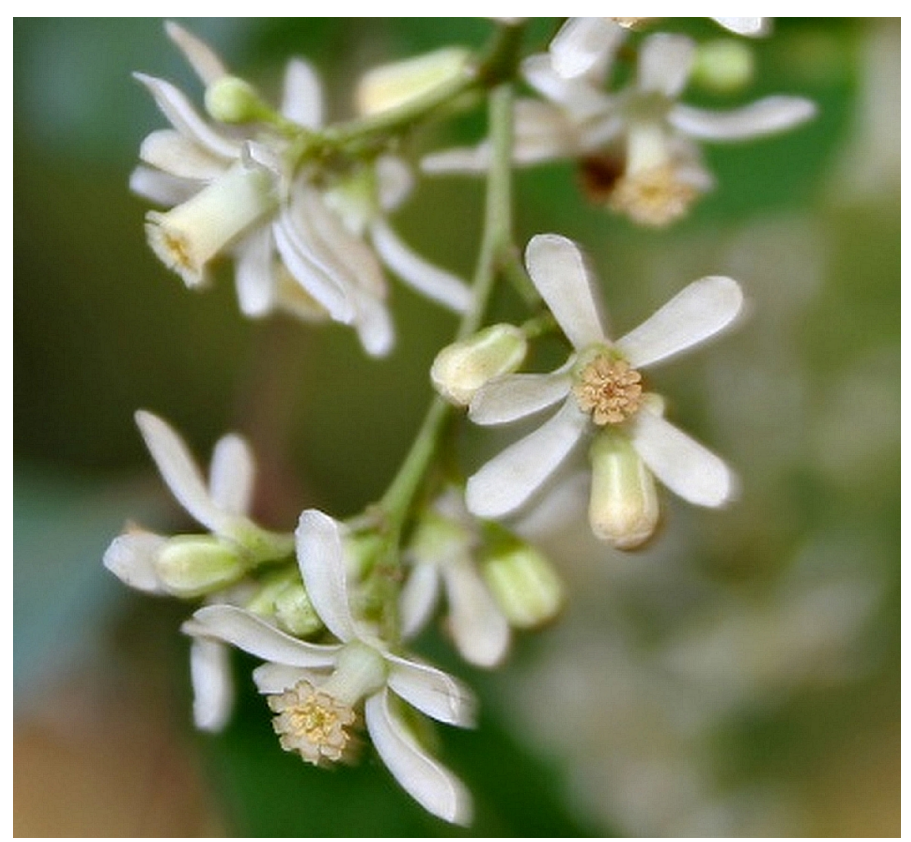

Figure 13. Flowers from Neem Tree

Neem kills some infectious organisms, contributes to the immune response at various levels, this increases the possibility that the body fight bacterial infections alone, viral and fungal. Neem increases the production of antibodies, improves the response of immune cells that release mediators white blood cells. For Diabetes: Neem extract orally reduces insulin requirements by between $30 \%$ and $50 \%$ to people who are insulin dependent. With Cancer: polysaccharides and limonoids found in the bark, leaves and Neem oil reduces tumors and cancer [39].

\subsection{Passiflora edulis Sims}

Another plant which has been described with therapeutic applications is the genus Passiflora, whics comprises about 500 species and is the largest in the family Passifloraceae. Passiflora edulis Sims is native from the Brazilian Amazon, known by the common name for passion fruit $[40,41]$. The word passion comes from the Portuguese- Brazilian passion fruit, which means food prepared in Totuma [41, 42].

Passiflora edulis (Figure 14) is a widely cultivated species in tropical and subtropical countries, there are two varieties: Passiflora edulis Sims var. flavicarpa, whose fruits are yellow and Passiflora edulis Sims var. purple, with purple fruits and adapts to higher ground [42].

Passion fruit (Figure 15) is a woody perennial, climbing habit and rapid development, which can reach up to $10 \mathrm{~m}$ long, the leaves are simple, alternate, and a tendril conestipules in the 
armpit, with serrated margins, the flowers (Figure 16) are solitary and axillary, fragrant and showy, the fruit is a spherical berry, globose or ellipsoid, measuring $10 \mathrm{~cm}$ in diameter and weighs up to $190 \mathrm{~g}$, yellow or purple, with a highly aromatic pulp [43].

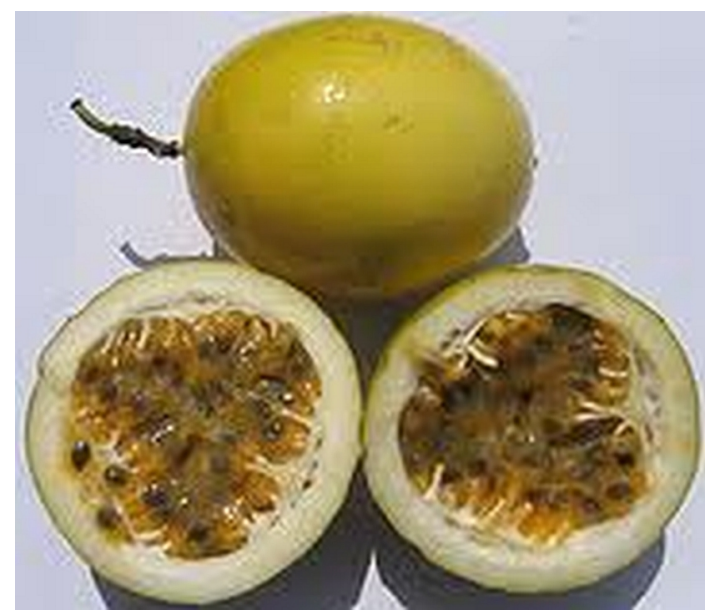

Figure 14. Passion fruit

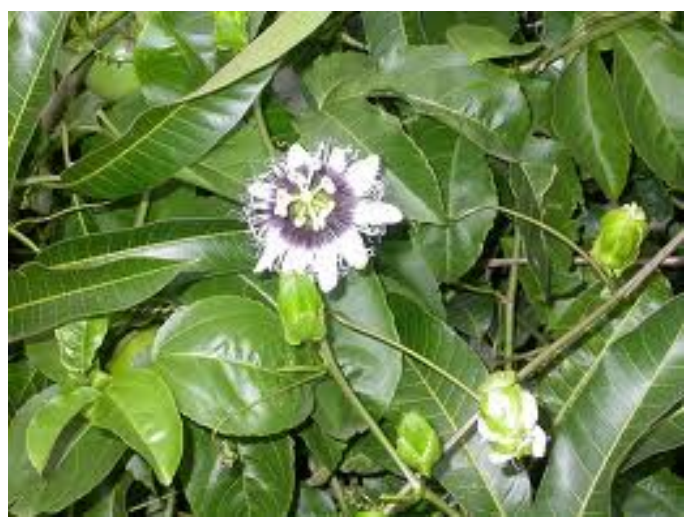

Figure 15. Leaves and flower of passion fruit

The ethnopharmacological information reveals that Passiflora edulis Sims has been used in traditional medicine around the world. In India, the fresh leaves of this plant are boiled in small amount of water and the extract is drunk to treat dysentery and hypertension, and the fruits are eaten to relieve constipation. In South America, native people drink the tea leaves and flowers as a sedative, infusion of the aerial parts is used in the treatment of tetanus, epi- 
lepsy, insomnia and hypertension is also indicated as a muscle relaxant, diuretic, to treat stomach aches, fever and intestinal tumors[44].

The phytochemical study of Passiflora edulis Sims (Passifloraceae) shows the presence of glycosides, including passiflorine, flavonoid glycosides: luteolin-6-Cchinovóside, cyanogenic glycosides, alkaloids harman, triterpenes and saponins, phenols, carotenoids, anthocyanins, L-ascorbic acid, $\gamma$-lactones, esters, volatile oils, eugenol, amino acids, carbohydrates and minerals [45].

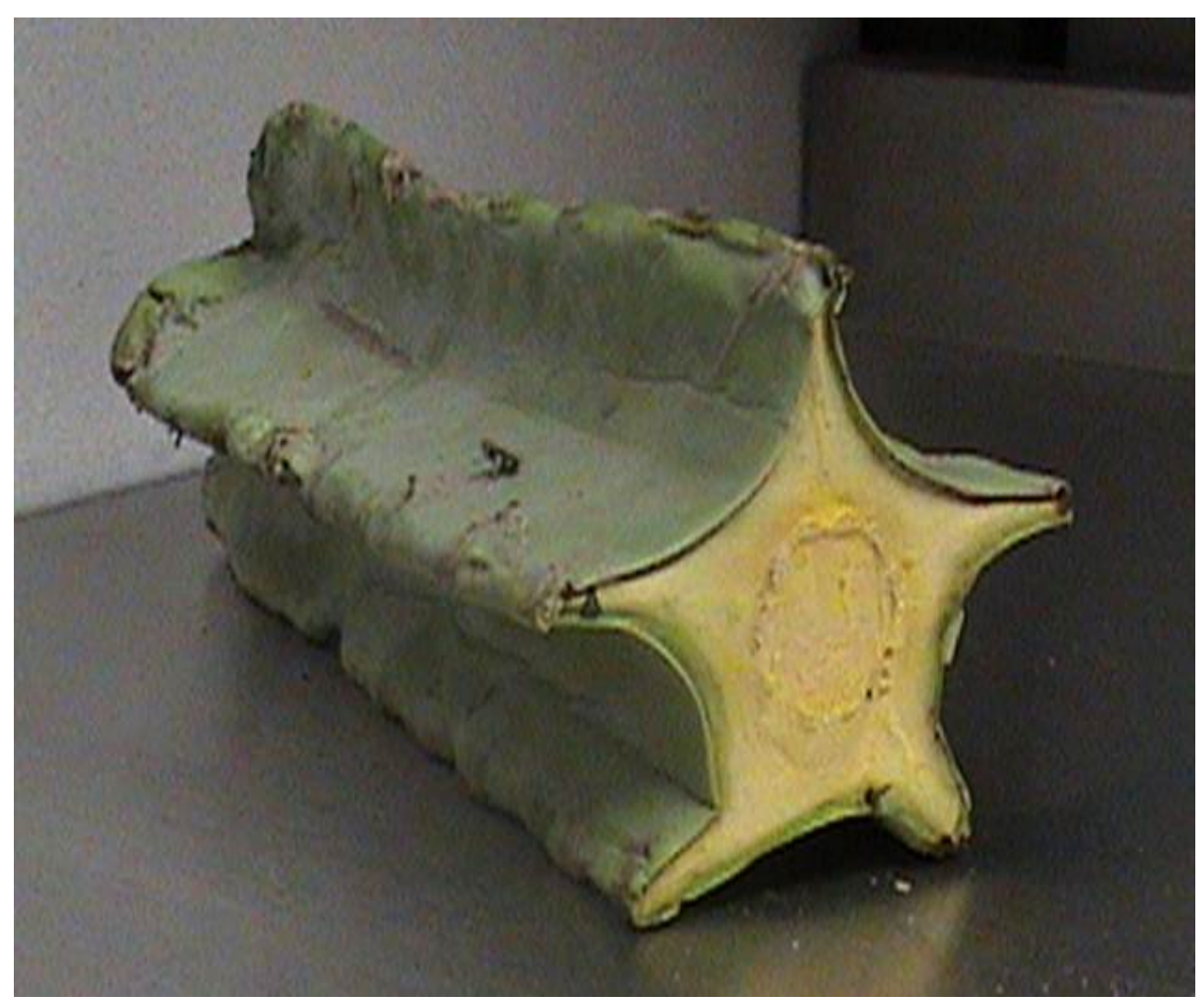

Figure 16. Five ribs cladode from Musaro (Lophocereus sp )

\subsection{Lophocereus $\mathrm{sp}$}

Gender Lophocereus sp. (Figure 17) develops as a succulent plant which presents a plus size and can reach $7 \mathrm{~m}$ tall. These cacti have a columnar development right, has ribbed stems that 
branch with age. The flowers are nocturnal, appear only on copies of more than two meters high and are colored green, but in the four seasons can take a pink color, the stem proliferation and leads to masses of slender spines long they can get to cover it completely. Multiply by seeds in spring or summer. These plants are drought resistant so as to avoid daily watering and exposure to damp, besides being very sensitive to frost. But they need full sun and well drained soils. It is endemic to Baja California Sur, Baja California and Sonora in Mexico and Arizona in the United States It is a common species that has spread efficiently over the worldwide. The fruits are edible, but are hard to come by competition with birds and insects. This plant has curative properties. Southeastern Mexican indians prepare a tea from the pulp and skin of the cactus to relieve arthritis. Some members of this ethnic group say the plants with five ribs are very good for treating cancer. For diabetes: using the Musaro with a seven-pointed cladode, boiled in 1 liter of water, strain and drink three glasses of cooking, one before each meal. It is also widely used to treat ulcers, wounds, and stomach diseases.

Musaro or gooseberry is the tea made by slicing sections fifteen or twenty two inches long from the stems of cactus. These cuts are then placed in a container large enough to contain five gallons of water and boiled for eight to ten hours until the liquid is reduced to approximately one gallon. People take this treatment for serious stomach diseases but they should drink tea in large amount. From extracts of Lophocereus sp two compounds have been isolated: pylocereine and lophocine a dimeric alkaloid with cytotoxic activity $[46,47]$.

\subsection{Cecropia obtusifolia Bertolt}

\section{Family: Cecropiaceae}

Common name: The names that are known are "guarumbo", "chancarro", "hormiguillo", "chiflón" and "koochlle" among others. This plant is widely used by people suffering from type 2 diabetes. It is known mainly in rural areas.

Botanical description: A tree $20 \mathrm{~m}$ tall, commonly grows in tropical rain forests. Its trunk is straight and presents a cavity where you can find some ants inside it, with branches that grow along this horizontally. The leaves are placed in a spiral on the branches. They have a deep green on the upper surface of the leaf and gray on the back (Figure 18).

Distribution in Mexico: located along the coasts of Tamaulipas and San Luis Potosi to Tabasco on the side of the Gulf of Mexico and Sinaloa to Chiapas Pacific side. Traditionally the dried leaves $(15 \mathrm{~g})$ are heated in water $(500 \mathrm{~mL})$ and the result is an infusion which is then filtered and taken as "daily water", cold infusion is often consumed in hot weather. States where is often used as traditional medicine this plant are: Hidalgo, Guerrero, Veracruz, Yucatan, Campeche, Tabasco, Mexico State, Oaxaca and Chiapas. It is reported that this plant contains $\beta$-sitosterol, stigmasterol, 4-ethyl-5-(n-3 valeroil)-6-hexahydrocoumarins. From butanol extracts were isolated chlorogenic acid and isorientin [48, 49]. 


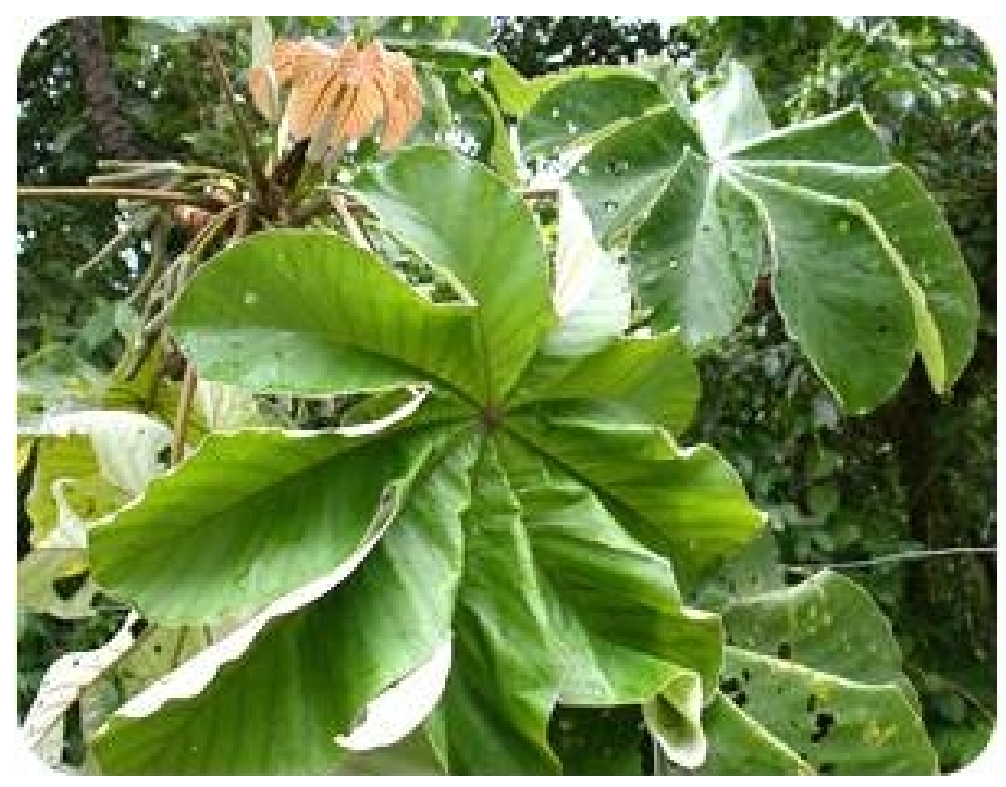

Figure 17. Guarumbo (Cecropia obtusifolia Bertolt) leaves.

\section{Conclusion}

The plant kingdom has been the best source of remedies for curing a variety of disease and pain. This is why medicinal plants have played a key role in the worldwide maintenance of health. Traditional herbal medicine is intimately related to the Mexican popular culture; its use has origins based on ancestral knowledge. Natural products of higher plants are an important source of therapeutic agents; therefore, many research groups are currently screening the different biological activities of plants. Mexico has an extensive variety of plants; it is the fourth richest country worldwide in this aspect. Some 25000 species are registered, and it is thought that there are almost 30000 not yet described. Natural antioxidants that are present in herbs and spices are responsible for inhibiting or preventing the deleterious consequences of oxidative stress. Spices and herbs contain free radical scavengers like polyphenols, flavonoids and phenolic compounds, having antioxidant activities, Indeed all these plant studied have several biological effects and they could also be used as a source of natural antioxidants. Further pharmacological studies are underway to identify the active constituents of the plant extracts responsible for the showed activities. As a final comment, compounds in plants are of great importance for the treatment of several chronic and degenerative diseases like diabetes and cancer, among others. For that reason the use in traditional medicine is of great interest in order to know the activity and the mechanism of action of these compounds which could be used for the treatment and prevention of that mentioned 
diseases, which are associated nowadays with stress, fast food diets and lack of daily exercise, just to name a few factors.

\section{Acknowledgments}

The authors wants to thank the ENCB-IPN for the support received for this work through the SIP projects 20120789 and 20120899.

\section{Author details}

Jorge Alberto Mendoza Pérez ${ }^{1}$ and Tomás Alejandro Fregoso Aguilar²*

1 Department of Environmental Systems Engineering at National School of Biological Sciences-National Polytechnic Institute. Mexico, D.F., Mexico

2 Department of Physiology at National School of Biological Sciences-National Polytechnic Institute. Mexico, D.F., Mexico

\section{References}

[1] PIETTA, P. G. (2000) Flavonoids as Antioxidants, Journal Natural Product, 63: 10351042.

[2] Rivera Arce E, Morales González J A, Fernández Sánchez A M, Bautista Ávila M, Vargas Mendoza N, Madrigal Santillán E O. (eds.) Chemistry of Natural Antioxidants and Studies Performed with Different Plants Collected in Mexico, (2009) 227-238

[3] Devasagaya T P, Tilak J C, Boloor K K. Free Radicals and Antioxidants in Human Health: Currens Status and Future Prospects. J. Assoc. Physicians India. 2004; 52:794-804.

[4] ACS. Chemistry. España:Reverte; 2010. p.460-65

[5] Camacho Luis A, Mendoza Pérez J A, The Ephemeral Nature of Free Radicals: Chemistry and Biochemistry of Free Radicals. In: Morales González J A, Fernández Sánchez A M, Bautista Ávila M, Vargas Mendoza N, Madrigal Santillán E O. (eds.) Antioxidants and Chronic Degenerative Diseases. México: Ciencia al Día; 2009. p. 27-76

[6] VanderJagt T J, Ghattas R, VanderJagt D J, Crossey M, Glew R H. Comparison of the Total Antioxidant Content of 30 Widely Used Medicinal Plants of New Mexico. Life Sci. 2002; 70: 1035-1040. 
[7] Bors W, Heller W, Michael C, Saran, M. Radical Chemistry of Flavonoids Antioxidants. Advances in Experimental Medicine and Biology. 1990; 264: 165-170.

[8] Ballester M. Antioxidants, Free Radicals and Health. A Physic-Organic Chemistry View. Med Clinc (Barc).1996;107:509-515.

[9] Bagchi D, Bagchi M, Stohs S J, Das D K, Ray S D, Kuszynski C A. Free Radicals and Grape Seed Proanthocyanidin Extract: Importance in Human Health and Disease Prevention. Toxicology. 2000; 148:187-197.

[10] Tedesco I, Russo M, Russo P, Iacomino G, Russo G L, Carraturo A. Antioxidant Effect of Red Wine Polyphenols on Red Blood Cells. The Journal of Nutritional Biochemistry. 2000; 11(2):114-119.

[11] Fernandez-Pachon, M S, Villano D, Garcia-Parrilla M C, Troncoso A M. Antioxidant Activity of Wines and Relation with their Polyphenolic Composition. Analytica Chimica Acta.2004; 513(1):113-118.

[12] Fernandez-Pachon, M. S., Villano, D., Troncoso, A. M., Garcia-Parrilla, M. C. Determination of the Phenolic Composition of Sherry and Table White Wines by Liquid Chromatography and their Relation with Antioxidant Activity. Analytica Chimica Acta. 2006; 563(1-2):101-108.

[13] Cimino, F., Sulfaro, V., Trombetta, D., Saija, A., Tomaino, A. Radicalscavenging Capacity of Several Italian Red Wines. Food Chemistry. 2007;103(1):75-81.

[14] Arnous, A., Makris, D. P., Kefalas, P. Correlation of Pigment and Flavanol Content with Antioxidant Properties in Selected Aged Regional Wines from Greece. Journal Of Food Composition And Analysis. 2002; 15(6):655-665.

[15] Minussi, R. C., Rossi, M., Bologna, L., Cordi, L., Rotilio, D., Pastore, G. M. Phenolic Compounds and Total Antioxidant Potential of Commercial Wines. Food Chemistry. 2003; 82(3): 409-416.

[16] Nava Ch. G, Veras G. M. E. Epidemiology of diabetes In: Morales G.J.A., Madrigal S.E.O., Nava Ch.G., Durante M.I., Jonguitud F.A., Esquivel S. J. (eds.) Diabetes 2nd. ed. Universidad Autónoma del Estado de Hidalgo: México; 2010. p.57 - 63.

[17] Fernández S. A.M. (2009). Antioxidants and diseases: Obesity. In: Morales González J A, Fernández Sánchez A M, Bautista Ávila M, Vargas Mendoza N, Madrigal Santillán E O. (eds.) Antioxidants and Chronic Degenerative Diseases. México: Ciencia al Día; 2009. p.411-25

[18] Posmontier B. The Medicinal Qualities of Moringa Oleifera. USA:Lippincott Williams \& Wilkin; 2011. p. 80-87

[19] Fragoso Antonio S. Antioxidant and Antigenotoxic Effects of Cranberry Juice. MsC Thesis. National School of Biological Sciences-National Polytechnic Institute; 2011. 
[20] Castilla, D. Phytochemical and Biological Studies of Leaf Extract and Fruit of Morinda citrifolia (Noni) in a Mouse Model of Diabetes. Bachelor Thesis. National School of Biological Sciences-National Polytechnic Institute; 2012.

[21] Lin C C, Huang P C. Antioxidant and Hepatoprotective Effects of Acanthopanax senticosus. Phytother. Res. 2002; 14: 489-494.

[22] Perry E K, Pickering A T, Wang W W, Houghton P J, Perru N S Medicinal Plants and Alzheimer's Disease:from Ethnobotany to Phytotherapy . J. Pharm. Pharmacol. 1999; 51: 527-534.

[23] Schinella G R, Tournier H A, Prieto J M, Mordujovich de Buschiazzo P, Ríos J L. Antioxidant Activity of Antiinflammatory Plant Extracts. Life Sci. 2002; 70: 1023-1033.

[24] Velázquez E, Tournier HA, Mordujovich de Buschiazzo P, Saavedra G, Schinella GR. Antioxidant activity of Paraguayan plant extracts. Fitoterapia. 2003; 74: 91-97.

[25] Moure A, Franco D, Sineiro J, Domínguez H, Núñez JM, Lema MJ. Evaluation of Extracts from Gevuina avellana Hulls as Antioxidants. J. Agric. Food Chem. 2000; 48: 3890-3897.

[26] Singleton VL, Rossi JA Colorimetry of Total Phenolics with Phosphomolybdic-Phosphotungstic Acid Reagents. Am. J. Enol. Vitinicult. 1965; 16: 55-61.

[27] Takao T, Kitatani F, Watanabe N, Yagi A, Sakata K A Simple Screening Method for Antioxidants and Isolation of Several Antioxidants Produced by Marine Bacteria from Fish and Shellfish. Bioscience. Biotechnol. Biochem. 1994; 58: 1780-1783.

[28] Miller H E. A Simplified Method for the Evaluation of Antioxidants. J. Am. Oil Chem. Soc. 1971; 48: 92-97.

[29] Monroy-Ortíz C, Castillo E P. Medicinal Plants Used in Morelos State. UAEM: México, 2000. p. 20-50

[30] Morales-Cifuentes C, Gómez-Serranillos MP, Iglesias I, Villar del Fresno AM. Neuropharmacological profile of ethnomedicinal plants of Guatemala J. Ethnopharmacol. 2001; 76: 223-228.

[31] Robak J, Gryglewski R. J. Flavonoids are scavengers of superoxide anions.Biochemical Pharmacology.1988; 37(5):837-841.

[32] Brandwilliams W, Cuvelier M E, Berset C. Use of a Free-Radical Method to Evaluate Antioxidant Activity. Food Science and Technology-Lebensmittel- Wissenschaft \& Technologie.1995; 28(1): 25-30.

[33] Cimino F, Sulfaro V, Trombetta D, Saija A, Tomaino A. Radicalscavenging Capacity of Several Italian Red Wines. Food Chemistry. 2007; 103(1): 75-81

[34] Sreelatha S, Padma P.R. Antioxidant Activity and Total Phenolic Content of Moringa Oleifera Leaves in Two Stages of Maturity. Plant Foods Hum Nutr. 2009; 64:303-311. 
[35] De Las Heras B, Slowing K, Benedí J, Carreto E, Ortega T, Toledo C, Bermejo P, Iglesias I, Abad MJ, Gómez-Serranillos P, Liso PA, Villar A, Chiriboga X. Antiinflamatory and Antioxidant Activity of Plants Used in Traditional Medicine in Ecuador. J. Ethnopharmacol. 1998; 61: 161-166.

[36] Faustino R S, Clark T. A, Sobrattee S, Czubryl M. P, Pierce G. N. Differential Antioxidant Properties of Red Wine in Water Soluble and Lipid Soluble Peroxyl Radical Generating Systems. Molecular And Cellular Biochemistry. 2004; 263(1):211-215.

[37] Dinis T. C. P, Madeira V. M. C, Almeida L. M. Action of Phenolic Derivates (Acetoaminophen, Salicylate, And 5-Aminosalicylate) as Inhibitors of Membrane Lipid Peroxidation and as Peroxyl Radical Scavengers. Archive Of Biochemistry And Biophysics. 1994; 315:161-169.

[38] Huang D. J, Ou B. X, Hampsch-Woodill M, Flanagan J. A, Prior R. L. High-Throughput Assay of Oxygen Radical Absorbance Capacity (ORAC) Using a Multichannel Liquid Handling System Coupled with a Microplate Fluorescence Reader in 96-Well Format. Journal of Agricultural and Food Chemistry. 2002; 50(16):4437-4444.

[39] Abu Syed Md. Mosaddek and Md. Mamun Ur Rashid. A Comparative Study of the Anti-Inflammatory Effect of Aqueous Extract of Neem Leaf and Dexamethasone. Bangladesh J Pharmacol. 2008; 3: 44-47

[40] Arteaga S, Andrade-Cetto A, Cárdenas R. Larrea tridentata (Creosote bush), an Abundant Plant of Mexican and US-American Deserts and its Metabolite Nordihydroguaiaretic Acid. J. Ethnopharmacol. 2005; 98: 231 - 239.

[41] Mareck U, Herrmann K, Galensa R, Wray V. The 6-Cchinovoside and 6-C-Fucoside of Luteolin from Passiflora edulis. Phytochemistry. 1991; 30: 3486-7.

[42] Christensen J, Jaroszewski J. Natural Glycosides Containing Allopyranose from the Passion Fruit Plant Circular Dichroism of Benzaldehyde Cyanohydrin Glycosides. Org Lett. 2001; 3:2193-5.

[43] Seigler D, Pauli G, Nahrstedt A, Leen R. Cyanogenic Allosides and Glucosides from Passiflora edulis and Carica papaya. Phytochemistry. 2002; 60: 873-82.

[44] Slaytor M, McFarlane I. The Biosynthesis and Metabolism of Harman in Passiflora edulis. Phytochemistry. 1968; 7:605-11.

[45] Shawan K, Dhawan S, Sharma A. Passiflora: a Review Update. Journal of Ethnopharmacology. 2004; 94: 1-23.

[46] Andrade, C. A, Heinrich B M. Mexican Plants with Hypoglycemic Effect Used in the Treatment of Diabetes. Journal Of Ethnopharmacology. 2005; 99:325-348.

[47] Andrade, C. Hipoglicemic Effect of Cecropia Obtusifolia on Streptozotocin Diabetic Rats. Journal Of Ethnopharmacology. 2001; 78(2-3):145-149.

[48] Hicks S. Desert Plants and the People. The Naylor Company Book:San Antonio, Texas; 2009. p. 35-37 
[49] Escalante J.S. Our Plants from the Sonora State http://www.apnsac.org. (Accesed 15 July 2012) 
